\title{
Use of remotely sensed and ancillary data for estimating forest gross primary productivity in Italy
}

\author{
Fabio Maselli ${ }^{\mathrm{a}, *}$, Anna Barbati ${ }^{\mathrm{b}}$, Marta Chiesi ${ }^{\mathrm{a}}$, Gherardo Chirici ${ }^{\mathrm{c}}$, Piermaria Corona ${ }^{\mathrm{b}}$ \\ a IBIMET-CNR, Via Madonna del Piano 10, 50019 Sesto Fiorentino (FI), Italy \\ ${ }^{\mathrm{b}}$ DISAFRI, University of Tuscia, Italy \\ c DISTAF, University of Florence, Italy
}

Received 26 August 2005; received in revised form 24 November 2005; accepted 27 November 2005

\begin{abstract}
The current paper describes the development and testing of a procedure which can use widely available remotely sensed and ancillary data to assess large-scale patterns of forest productivity in Italy. To reach this objective a straightforward model (C-Fix) was applied which is based on the relationship between photosynthetically active radiation absorbed by plant canopies and relevant gross primary productivity (GPP). The original C-Fix methodology was improved by using more abundant ancillary information and more efficient techniques for NDVI data processing. In particular, two extraction methods were applied to NDVI data, derived from two sensors (NOAA-AVHRR and SPOT-VGT) to feed C-Fix. The accuracy of the model outputs was assessed through comparison with annual and monthly values of forest GPP derived from eight eddy covariance flux towers. The results obtained indicated the superiority of SPOT-VGT over NOAA-AVHRR data and a higher efficiency of the more advanced NDVI extraction method. Globally, the procedure was proved to be of easy and objective implementation and allowed the evaluation of mean productivity levels of existing forests on the national scale.
\end{abstract}

(C) 2005 Elsevier Inc. All rights reserved.

Keywords: Forest ecosystems; Gross primary productivity; Carbon uptake; C-Fix model; NOAA-AVHRR; SPOT-VGT

\section{Introduction}

The assessment of forest productivity on wide areas is important for both scientific and practical purposes. Such an assessment is in fact necessary to study the global carbon cycle and can produce information useful for planning and managing forest resources (Waring \& Running, 1998). Unfortunately, regional scale applications of field-based measurement techniques are economically expensive and time-consuming, due to the high spatial variability of the factors which affect forest production (climate, topography, soil fertility, management practices, etc.). Thus, a procedure mostly independent of field measurements and driven by remote sensing data would be extremely useful to yield spatial estimates of forest productivity (Running et al., 1999). Trials in this direction have already been made for some European countries, obtaining mixed

\footnotetext{
* Corresponding author. Tel.: +39 0554483055 .

E-mail address: maselli@ibimet.cnr.it (F. Maselli).
}

results probably linked to the data sources utilized and the procedures applied (Veroustraete et al., 2002, 2004).

This situation calls for improvement and careful testing of remote sensing based procedures capable of evaluating forest productivity on regional to national scales. A research effort was recently conducted to respond to these needs for the Italian national territory. The basic consideration underlying this effort was that substantial improvements in the estimation of forest productivity over large areas was obtainable by suitably integrating multi-source remotely sensed and ancillary data. The research therefore aimed at developing and testing a methodology of relatively simple implementation capable of utilizing widely available earth observation and ancillary data. Such a methodology was based on a straightforward model of forest productivity (C-Fix) which uses the relationship between photosynthetically active radiation absorbed by plant canopies (APAR) and the productivity of those canopies. This approach was a modification of the C-Fix model originally proposed by Veroustraete et al. (1994), which has been applied over several European countries (Veroustraete et al., 2002, 2004). The 